\title{
Explanatory Factors For Overall Instructor And Course Ratings
}

\author{
Sandip Mukherji, (E-mail: smukherji@howard.edu), Howard University
}

\begin{abstract}
Eight items explain $96 \%$ and $94 \%$ of variance in instructor and course ratings. Effectiveness of teaching methods and degree of learning have the greatest impact on instructor and course ratings. Instructor evaluations are influenced mainly by instructor items and course evaluations are impacted primarily by course items, but instructor items also influence course evaluations. Small classes have a significantly higher overall instructor performance rating than large classes and there are some differences between the explanatory factors for overall instructor performance and course evaluation in small and large classes.
\end{abstract}

\section{INTRODUCTION}

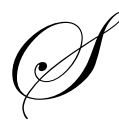

tudent evaluation of teaching (SET) instruments are widely used to evaluate the teaching performance of instructors. Seldin (1999) reported that $88 \%$ of deans use student ratings to evaluate teaching performance. Analyses and interpretations of SET responses are therefore of interest to teachers as well as administrators. SET forms provide ratings of overall performance as well as performance in key areas that are expected to significantly impact overall performance. Marsh (1984) identified nine important dimensions of teaching: learning/value, instructor enthusiasm, organization/clarity, group interaction, individual rapport, breadth of coverage, examinations/grades, assignments/readings, and workload/difficulty. Subsequently, Marsh (1987) reported that more than 30 different studies using factor analyses consistently found these nine factors. SET forms commonly incorporate most of these critical drivers of teaching performance. Centra (1993) and Braskamp and Ory (1994) found six common factors in student evaluation forms: course organization and planning, clarity and communication skills, teacher-student interaction and rapport, course difficulty and workload, grading and examinations, and student selflearning.

Although teaching effectiveness is multidimensional, its measurement need not be multidimensional. Centra (1980) reported that global questions on teaching effectiveness have the highest correlations with student achievement and Cohen (1981) indicated that student learning is more highly correlated with overall teaching effectiveness than with more specific items. Cashin and Downey (1992) showed that two global items - the instructor and the course each account for more than $50 \%$ of the variance in the weighted-composite criterion measure. They concluded that short forms could capture much of the information needed for summative evaluation and suggested that global items are the most useful student ratings for personnel decisions. Hativa and Raviv (1993) also supported the use of a global score for assessment purposes. Marsh and Roche (1997) suggested that a weighted average of specific SET factors would reflect the multidimensionality of SETs, but acknowledged that unresolved issues regarding the validity and utility of importance-weighted averages "dictate caution in pursuing this suggestion."

While researchers have suggested that overall ratings are the appropriate measures for administrative evaluations, specific SET items are more useful for the purpose of providing feedback to faculty. Relationships between overall ratings and specific SET items are of great interest to faculty seeking to improve their overall ratings. This study analyzed SETs for all three-credit undergraduate courses taught during the 2003-04 academic year at a business school accredited by the Association to Advance Collegiate Schools of Business International. Of the 323 courses taught during the year, 48 graduate courses were excluded from the analysis because graduate classes tend to be small and are rated somewhat more favorably than undergraduate courses (Marsh and Roche, 1997). In addition, 24 one-credit courses were omitted because these classes were generally large and not comparable to three-credit courses. 
The study sample consisted of 251 courses taught by 77 instructors in five departments: accounting; finance, international business, and insurance; information systems and decision sciences; management and hospitality management; and marketing. The mean (median) number of students enrolled in these courses was 28 (25) and the mean and median response rates for the SETs were both $60 \%$.

\section{STUDENT EVALUATION OF TEACHING QUESTIONNAIRE}

The SET questionnaire, shown in Appendix 1, was developed and adopted by the faculty of the business school after extensive review and discussions. It consists of ten items: four course evaluation items, four instructor evaluation items, and overall course and instructor evaluations. Students rate each item on a five-point scale ranging from very poor (1) to very good (5) and are also encouraged to provide written comments to explain or expand on the numerical evaluations. An important reason for adopting the short SET instrument was to give students more time for written comments, which can provide more specific, individualized feedback than numerical responses.

The correspondence between the SET items and the teaching dimensions identified by Marsh (1984) are shown in Appendix 2. The specific items of the broad teaching dimensions that match the SET items most closely are shown in parentheses. The nine dimensions identified by Marsh included overall course and instructor ratings as parts of two dimensions (learning value and enthusiasm, respectively). The SET instrument has two separate items for overall course and instructor ratings. This increase of two items is partly offset by combining two dimensions breadth of coverage and group interaction (which may not be relevant for all courses) - into one (effectiveness of teaching methods). The SET instrument therefore has ten items.

\section{RELATIONS BETWEEN GLOBAL RATINGS AND SPECIFIC ITEMS}

Several researchers have studied relationships of overall instructor and course ratings with specific SET items. Marsh (1984) indicated that aggregate assessments are not significantly influenced by non-teaching variables and Marsh (1994) showed that the overall summative evaluation is positively related to other teaching performance items in the SET instrument. Baird (1987) found that students' perceived learning has correlations of 0.88 with course evaluations and 0.86 with instructor evaluations, and it explains a much larger portion of rating variance than actual course grades. Marsh and Dunkin (1992) and Centra (1993) reported that workload has a weak positive correlation with ratings. Braskamp and Ory (1994) found a low positive correlation between expected grades and student ratings. Marsh and Roche (1997) indicated that average SETs are correlated with average grades, but pointed out that higher grades may reflect superior learning or preexisting differences rather than grading leniency.

Mason et al. (1995) noted that although student perceptions of teaching effectiveness are also affected by the characteristics of courses and students, only the instructors' characteristics should be included in measures of teaching effectiveness.

\section{AVERAGE RATINGS OF TEACHING EVALUATION ITEMS AND SIGNIFICANT DIFFERENCES}

SETs are scored with Likert scales, which provide ordinal data, but they are commonly used with interval techniques for scales containing at least five items. Jaccard and Wan (1996) reviewed the literature and indicated that even severe departures from intervalness do not appear to have much impact on statistical tests. Labovitz (1970) and Kim (1975) reported that correlation and other parametric coefficients are robust to ordinal distortion. In their study of the Student Instructional Report, Mason et al. (1995) noted that numerical codes attach a cardinal component to the variables and "formal hypothesis tests indicate that the cardinality assumption is not invalid." Since the SET instrument analyzed in this study requires students to score each item on a scale of 1 to 5 , it is plausible that they focus on the numerical scores rather than on the words associated with the scores. Consistent with this expectation, although the scales were revised downwards from a range of unsatisfactory to outstanding in the previous instrument to a more extreme low of very poor and a milder high of very good in the new instrument, the average overall rating for all courses was close to 4 with both instruments. 
Marsh and Roche (1997) indicated that with a sufficient number of students, class-average SETs are as reliable as objective tests and suggested that the class average is the appropriate unit of analysis. Panel A of Table 1 shows that for the 251 courses in the sample, the three highest means are all for instructor performance items - interest in student learning, overall instructor performance, and organization of course. The lowest means are for an instructor performance items - effectiveness of teaching methods - and two course evaluation items - appropriateness of difficulty and degree of learning. Overall instructor performance is rated higher than all the other items except interest in student learning, suggesting that the overall performance of instructors is perceived to be better than their performance on most of the individual items.

The results of t-tests in Panel B show that the overall instructor performance rating is significantly higher than the overall course evaluation rating and the mean rating of the four specific instructor performance items. The overall course evaluation rating, however, is not significantly different from the mean rating of the four specific course evaluation items.

Table 1

Average Ratings of Teaching Evaluation Items and Significant Differences

Panel A. Average Ratings of Teaching Evaluation Items

$\begin{array}{llc}\text { Rank } & & \text { Mean } \\ 1 & \text { Interest in student learning } & 4.22 \\ 2 & \text { Overall instructor performance } & 4.06 \\ 3 & \text { Organization of course } & 4.05 \\ 4 & \text { Effectiveness of course materials } & 4.02 \\ 5 & \text { Ability to communicate } & 4.00 \\ 6 & \text { Fairness of grading system } & 3.98 \\ 7 & \text { Overall course evaluation } & 3.97 \\ 8 & \text { Degree of learning } & 3.96 \\ 9 & \text { Appropriateness of difficulty } & 3.95 \\ 10 & \text { Effectiveness of teaching methods } & 3.83\end{array}$

Panel B. Differences Between Overall Instructor Performance, Course Evaluation, and Specific Items

$\begin{array}{lrccr} & \text { Mean } & \text { Difference } & \text { T-stat } & \text { P-value } \\ \text { Overall instructor performance } & 4.06 & & & \\ \text { Overall course evaluation } & 3.97 & 0.09 & 5.35 & 0.00 \\ \text { Overall instructor performance } & 4.06 & & & \\ \text { Specific instructor performance items } & 4.02 & 0.04 & 4.29 & 0.00 \\ \text { Overall course evaluation } & 3.97 & & & \\ \text { Specific course evaluation Items } & 3.98 & -0.01 & -0.58 & 0.56\end{array}$

\section{CORRELATIONS OF OVERALL INSTRUCTOR PERFORMANCE AND COURSE EVALUATION RATINGS WITH OTHER ITEMS}

In Table 2, Panel A indicates that overall instructor performance has stronger correlations of 0.90 to 0.96 with the four specific instructor performance items than the correlations of 0.84 to 0.89 with the four specific course evaluation items, suggesting that instructors are judged mainly on the basis of instructor performance items. Panel B shows that overall course evaluation has strong correlations of 0.85 to 0.93 with the four specific course evaluation items. However, overall course evaluation is more strongly correlated with an instructor performance item effectiveness of teaching methods - than with all the course evaluation items except degree of learning, which has a similar correlation.

Overall instructor performance is most strongly correlated with effectiveness of teaching methods and ability to communicate, and least strongly correlated with fairness of grading system and appropriateness of difficulty. 
Overall course evaluation is most strongly correlated with degree of learning and effectiveness of teaching methods, and least strongly correlated with fairness of grading system and interest in student learning. Both overall instructor performance and overall course evaluation have very strong correlations with effectiveness of teaching methods and the lowest correlations with fairness of grading systems. Overall instructor performance and overall course evaluation have a very strongly correlation of 0.93 , which is even higher than the correlation of 0.81 between overall instructor and course effectiveness reported by McKone (1999).

Table 2

Correlations of Overall Instructor Performance and Course Evaluation Ratings with other Items

Rank Item

Correlation

Panel A. Correlations of Overall Instructor Performance Rating with other Items

$\begin{array}{lll}1 & \text { Effectiveness of teaching methods* } & 0.96 \\ 2 & \text { Ability to communicate* } & 0.95 \\ 3 & \text { Overall course evaluation } & 0.93 \\ 4 & \text { Interest in student learning* } & 0.92 \\ 5 & \text { Organization of course* }^{*} & 0.90 \\ 6 & \text { Degree of learning^ } & 0.89 \\ 7 & \text { Effectiveness of course materials } & 0.85 \\ 8 & \text { Appropriateness of difficulty^} & 0.84 \\ 9 & \text { Fairness of grading system } & \end{array}$

\section{Panel B. Correlations of Overall Course Evaluation Rating with other Items}

$\begin{array}{lll}1 & \text { Degree of learning^ } & 0.93 \\ 2 & \text { Effectiveness of teaching methods* } & 0.93 \\ 3 & \text { Overall instructor performance } & 0.93 \\ 4 & \text { Effectiveness of course materials } & 0.90 \\ 5 & \text { Ability to communicate* } & 0.90 \\ 6 & \text { Appropriateness of difficulty } & 0.90 \\ 7 & \text { Organization of course* } & 0.89 \\ 8 & \text { Interest in student learning* } & 0.87 \\ 9 & \text { Fairness of grading system } & \\ \text { *Instructor performance items } & 0.85 \\ { }^{\wedge} \text { Course evaluation Items }\end{array}$

The correlations indicate that the nine individual items explain between $71 \%$ and $92 \%$ of variance in overall instructor performance ratings and $72 \%$ to $86 \%$ of variance in overall course evaluation ratings. These findings are consistent with the observation of Mason et al. (1995) that the responses of most students to the aggregate questions are "logical extensions of their responses to the more specific questions."

\section{REGRESSIONS OF OVERALL INSTRUCTOR PERFORMANCE RATINGS}

Panel A of Table 3 reveals that the instructor performance items explain $96 \%$ of variance in overall instructor performance and all the coefficients are significantly positive. The instructor performance items that have the strongest impact on overall instructor performance are effectiveness of teaching methods and ability to communicate. Panel B shows that the course evaluation items explain $85 \%$ of variance in overall instructor performance and appropriateness of difficulty is the only item that is not significantly positive at $5 \%$ level. Degree of learning and fairness of grading system are the course evaluation items that have the greatest influence on overall instructor performance. In Panel $\mathrm{C}$, combining the course evaluation items with the instructor performance items does not change the adjusted R-square or the significance of the instructor performance items. The only course evaluation item 
with a significantly positive coefficient in this regression is degree of learning. These findings indicate that instructor evaluations are impacted mainly by instructor performance items.

Table 3

Regressions of Overall Instructor Performance Rating

Items Coefficient P-value Adjusted R-Square

Panel A. Regressions with Specific Instructor Performance Items

$\begin{array}{lccc}\text { Intercept } & -0.05 & 0.44 & 0.96 \\ \text { Effectiveness of teaching methods } & 0.28 & 0.00 & \\ \text { Ability to communicate } & 0.26 & 0.00 \\ \text { Interest in student learning } & 0.24 & 0.00 \\ \text { Organization of course } & 0.24 & 0.00\end{array}$

Panel B. Regressions with Specific Course Evaluation Items

$\begin{array}{lccc}\text { Intercept } & -0.58 & 0.00 & 0.85 \\ \text { Degree of learning } & 0.51 & 0.00 & \\ \text { Fairness of grading system } & 0.35 & 0.00 \\ \text { Effectiveness of course materials } & 0.18 & 0.03 \\ \text { Appropriateness of difficulty } & 0.12 & 0.09\end{array}$

Panel C. Regressions with Specific Instructor Performance and Course Evaluation Items

$\begin{array}{lcc}\text { Intercept } & 0.06 & 0.51 \\ \text { Effectiveness of teaching methods } & 0.29 & 0.00 \\ \text { Ability to communicate } & 0.25 & 0.00 \\ \text { Interest in student learning } & 0.24 & 0.00 \\ \text { Organization of course } & 0.24 & 0.00 \\ \text { Degree of learning } & 0.11 & 0.01 \\ \text { Fairness of grading system } & 0.05 & 0.09 \\ \text { Effectiveness of course materials } & -0.07 & 0.09 \\ \text { Appropriateness of difficulty } & -0.10 & 0.01\end{array}$

\section{REGRESSIONS OF OVERALL COURSE EVALUATION RATINGS}

In Table 4, Panel A indicates that course evaluation items explain 93\% of variance in overall course evaluation and all the coefficients are significantly positive. The course evaluation item that has the strongest impact on overall course evaluation is degree of learning. Panel B shows that the instructor performance items explain $89 \%$ of variance in overall course evaluation and all the coefficients are significantly positive. Effectiveness of teaching methods and organization of course are the instructor performance items that have the greatest influence on overall course evaluation. In Panel C, combining the instructor performance items with the course evaluation items marginally increases the adjusted R-square and all the course evaluation and instructor performance items, except interest in student learning, remain significantly positive at 5\% level. These results show that course evaluations are primarily based on course evaluation items, but instructor performance items also influence course evaluations. 
Table 4

Regressions of Overall Course Evaluation Rating

$\begin{array}{lccc}\text { Items } & \begin{array}{c}\text { Coefficient } \\ \text { Panel A. Regressions with Specific }\end{array} & \begin{array}{c}\text { P-value } \\ \text { Course Evaluation Items }\end{array} & \text { Adjusted R-Square } \\ \text { Intercept } & -0.41 & 0.00 & 0.93 \\ \text { Degree of learning } & 0.44 & 0.00 & \\ \text { Appropriateness of difficulty } & 0.24 & 0.00 & \\ \text { Fairness of grading system } & 0.22 & 0.00 & \\ \text { Effectiveness of course materials } & 0.20 & 0.00 & \end{array}$

Panel B. Regressions with Specific Instructor Performance Items

$\begin{array}{lll}\text { Intercept } & 0.52 & 0.00 \\ \text { Effectiveness of teaching methods } & 0.32 & 0.00 \\ \text { Organization of course } & 0.29 & 0.00 \\ \text { Ability to communicate } & 0.15 & 0.01 \\ \text { Interest in student learning } & 0.11 & 0.03\end{array}$

Panel C. Regressions with Specific Instructor Performance and Course Evaluation Items

$\begin{array}{lcc}\text { Intercept } & -0.14 & 0.16 \\ \text { Degree of learning } & 0.31 & 0.00 \\ \text { Appropriateness of difficulty } & 0.20 & 0.00 \\ \text { Fairness of grading system } & 0.16 & 0.00 \\ \text { Ability to communicate } & 0.12 & 0.00 \\ \text { Effectiveness of course materials } & 0.12 & 0.01 \\ \text { Effectiveness of teaching methods } & 0.11 & 0.02 \\ \text { Organization of course } & 0.09 & 0.01 \\ \text { Interest in student learning } & -0.06 & 0.11\end{array}$

\section{IMPACT OF CLASS SIZE ON OVERALL INSTRUCTOR PERFORMANCE RATINGS}

Centra (1980) reports a negative correlation between student ratings and class size. Marsh and Roche (1997) point out that the evidence that smaller classes receive higher student ratings than larger classes reflects the effect of class size on group interaction and individual rapport rather than a class-size bias in SETs. Panel A in Table 5 indicates that overall instructor performance is highest for the smallest class-size quintile and declines consistently up to the fourth quintile, but the largest class-size quintile has a higher instructor performance rating than the secondlargest quintile. This pattern is consistent with the non-linear relationship between class size and SET ratings reported by Holtfreter (1991).

Panel B shows that the smallest classes have a significantly higher overall instructor performance rating than the largest classes. The smallest and second-smallest classes combined also have a significantly higher overall instructor performance rating than the second-largest and largest classes combined. Panel $\mathrm{C}$ demonstrates that, for 42 pairs of courses taught by the same instructors, the smallest and second-smallest classes combined have a significantly higher overall instructor performance rating than the second-largest and largest classes combined. 
Table 5

Impact of Class Size on Overall Instructor Performance Ratings

Panel A. Mean Overall Instructor Performance Ratings for Classes of Different Sizes

$\begin{array}{cccc}\begin{array}{c}\text { Number of } \\ \text { Students }\end{array} & \begin{array}{c}\text { Number } \\ \text { of Classes }\end{array} & \begin{array}{c}\text { Mean Number of } \\ \text { Students Enrolled }\end{array} & \begin{array}{c}\text { Mean Overall Instructor } \\ \text { Performance Rating }\end{array} \\ 1-12 & 49 & 8 & 4.35 \\ 13-20 & 52 & 17 & 4.11 \\ 21-28 & 48 & 25 & 4.04 \\ 29-43 & 53 & 37 & 3.81 \\ 44-68 & 49 & 53 & 4.02\end{array}$

Panel B. Differences Between Mean Overall Instructor Performance Ratings of Classes of Different Sizes

\begin{tabular}{ccccc} 
Number of & Number & \multicolumn{3}{c}{ Instructor Performance Rating } \\
Students & of Classes & Mean & Difference & P-value \\
$1-12$ & 49 & 4.35 & & \\
$44-68$ & 49 & 4.02 & 0.33 & 0.01 \\
$1-20$ & 101 & 4.23 & & \\
$29-68$ & 102 & 3.91 & 0.32 & 0.00
\end{tabular}

Panel C. Difference between Mean Overall Instructor Performance Ratings of 42 Pairs of Small and Large Classes Taught by Same Professors

\begin{tabular}{lcccc} 
Class & Mean Number of & \multicolumn{3}{c}{ Instructor Performance Rating } \\
Size & Students Enrolled & Mean & Difference & P-value \\
Small (1-20) & 14 & 4.07 & & \\
Large $(29-68)$ & 44 & 3.78 & 0.29 & 0.00
\end{tabular}

\section{REGRESSIONS OF OVERALL INSTRUCTOR PERFORMANCE RATINGS FOR SMALL AND LARGE CLASSES}

To investigate possible differences between the explanatory factors, separate full-model regressions of overall instructor performance were run for small and large classes. Table 6 shows that for small classes, the adjusted $\mathrm{R}$-square is $95 \%$ and only the four instructor performance items are significantly positive. Consistent with the fullsample results in Table 3, effectiveness of teaching methods has the greatest impact on overall instructor performance in small classes also. For large classes, the explanatory power of the model is $98 \%$ and in addition to the instructor performance items, fairness of the grading system is also significantly positive. In contrast to the results for small classes, organization of the course has the greatest influence on the overall instructor performance in large classes. 
Table 6

Regressions of Overall Instructor Performance Rating for Small and Large Classes

Items

\author{
Coefficient
}

P-value

Adjusted R-Square

Panel A. Small Classes (1-20 Students)

$\begin{array}{lcc}\text { Intercept } & 0.27 & 0.06 \\ \text { Effectiveness of teaching methods } & 0.29 & 0.00 \\ \text { Interest in student learning } & 0.27 & 0.00 \\ \text { Organization of course } & 0.26 & 0.00 \\ \text { Ability to communicate } & 0.23 & 0.00 \\ \text { Degree of learning } & 0.09 & 0.15 \\ \text { Fairness of grading system } & -0.00 & 0.95 \\ \text { Effectiveness of course materials } & -0.05 & 0.38 \\ \text { Appropriateness of difficulty } & -0.13 & 0.03\end{array}$

Panel B. Large Classes (29-68 Students)

\begin{tabular}{|c|c|c|}
\hline Intercept & -0.25 & 0.06 \\
\hline Organization of course & 0.28 & 0.00 \\
\hline Interest in student learning & 0.27 & 0.00 \\
\hline Effectiveness of teaching methods & 0.23 & 0.00 \\
\hline Ability to communicate & 0.21 & 0.00 \\
\hline Fairness of grading system & 0.10 & 0.01 \\
\hline Degree of learning & 0.10 & 0.14 \\
\hline Effectiveness of course materials & -0.06 & 0.41 \\
\hline Appropriateness of difficulty & -0.06 & 0.31 \\
\hline
\end{tabular}

\title{
REGRESSIONS OF OVERALL COURSE EVALUATION RATINGS FOR SMALL AND LARGE CLASSES
}

Table 7 shows that the full-model regression of overall course evaluation for small classes has an adjusted Rsquare of $91 \%$ and only two course evaluation items - degree of learning and appropriateness of difficulty - have significantly positive coefficients. For large classes, the explanatory power is $98 \%$ and in addition to all the four course evaluation items, ability to communicate is also significantly positive.

Table 7

Regressions of Overall Course Evaluation Rating for Small and Large Classes

Items Coefficient P-value Adjusted R-Square

Panel A. Small Classes (1-20 Students)

$\begin{array}{lcc}\text { Intercept } & -0.01 & 0.95 \\ \text { Degree of learning } & 0.32 & 0.00 \\ \text { Appropriateness of difficulty } & 0.22 & 0.00 \\ \text { Effectiveness of teaching methods } & 0.15 & 0.06 \\ \text { Fairness of grading system } & 0.10 & 0.08 \\ \text { Organization of course } & 0.10 & 0.09 \\ \text { Ability to communicate } & 0.12 & 0.12 \\ \text { Effectiveness of course materials } & 0.07 & 0.32 \\ \text { Interest in student learning } & -0.08 & 0.29\end{array}$


Panel B. Large Classes (29-68 Students)

$\begin{array}{lcc}\text { Intercept } & -0.32 & 0.01 \\ \text { Degree of learning } & 0.35 & 0.00 \\ \text { Fairness of grading system } & 0.26 & 0.00 \\ \text { Effectiveness of course materials } & 0.25 & 0.00 \\ \text { Appropriateness of difficulty } & 0.19 & 0.00 \\ \text { Ability to communicate } & 0.16 & 0.00 \\ \text { Effectiveness of teaching methods } & 0.07 & 0.31 \\ \text { Organization of course } & -0.09 & 0.11 \\ \text { Interest in student learning } & -0.10 & 0.05\end{array}$

\section{CONCLUSIONS}

This study analyzed SETs for all three-credit undergraduate courses taught during the 2003-04 academic year at a business school accredited by the Association to Advance Collegiate Schools of Business International . The results show that the overall instructor performance rating is significantly higher than the overall course evaluation rating and the mean rating of the specific instructor performance items. The overall course evaluation rating, however, is not significantly different from the mean rating of the specific course evaluation items. Instructor evaluations are impacted mainly by instructor performance items, which explain $96 \%$ of variance in overall instructor performance. Course evaluations are primarily based on course evaluation items, which explain $93 \%$ of variance in overall course evaluation, but instructor performance items also influence course evaluations. Small classes have a significantly higher overall instructor performance rating than large classes and there are some differences between the explanatory factors for overall instructor performance and course evaluation in small and large classes.

\section{REFERENCES}

1. Baird, J.S., (1987). Perceived learning in relation to student evaluation of university instruction. Journal of Educational Psychology, 79, 90-91.

2. Braskamp, L. A. and Ory, J. C., (1994). Assessing faculty work: Enhancing individual and institutional performance. San Francisco: Josey-Bass.

3. Cashin, W. E. and Downey, R.G., (1992). Using global student rating items for summative evaluation. Journal of Educational Psychology, 84, 563-572.

4. Centra, J.A., (1980). The how and why of evaluating teaching. Engineering Education, 58, 438-481.

5. $\quad$ Centra, J. A., (1993). Reflective faculty evaluation. San Francisco: Josey-Bass.

6. Cohen, P.A., (1981). Student ratings of instruction and student achievement: A meta-analysis of multisection validity studies. Review of Educational Research, 51, 281-309.

7. Hativa, N. and Raviv, A., (1993). Using a single score for summative teacher evaluation by students. Research in Higher Education, 34, 625-646.

8. Holtfreter, R.E., (1991). Student rating biases: Are faculty fears justified? The Woman CPA, Fall, 59-62.

9. Jaccard, J. and Wan, C. K., (1996). LISREL approaches to interaction effects in multiple regression. Thousand Oaks, CA: Sage Publications.

10. Kim, J.O., (1975). Multivariate analysis of ordinal variables. American Journal of Sociology, 81, 261-298.

11. Labovitz, S., (1970). The assignment of numbers to rank order categories. American Sociological Review, 35, 515-524.

12. Marsh, H. W., (1984). Students' evaluation of university teaching: Dimensionality, reliability, validity, potential biases, and utility. Journal of Educational Psychology, 76, 707-754.

13. Marsh, H. W., (1987). Students' evaluations of university teaching: Research findings, methodological issues, and directions for future research. International Journal of Educational Research, 11, 253-388.

14. Marsh, H. W. and Dunkin, M., (1992). Students' evaluations of university teaching: A multidimensional perspective. In J. C. Smart (Ed.), Higher education: Handbook on theory and research, 8, 143-234. New York: Agathon Press.

15. Marsh, H.W., (1994). Weighting for the right criteria to validate student evaluations of teaching in the IDEA system. Journal of Educational Psychology, 86, 631-648. 
16. Marsh, H. W. and Roche, L. A., (1997). Making students' evaluations of teaching effectiveness effective: The critical issues of validity, bias, and utility. American Psychologist, 52, 1187-1197.

17. Mason, P. M., Steagall, J. W., and Fabritius, M. M., (1995). Student evaluations of faculty: A new procedure for using aggregate measures of performance. Economics of Educational Review, 14, 403-416.

18. McKone, K. E., (1999). Analysis of student feedback improves instructor effectiveness. Journal of Management Education, 23, 396-415.

19. Seldin, P., (1999). Changes in practices in evaluating teaching. Bolton, Massachusetts: Anker Publishing Company, Inc.

Appendix 1

Student Evaluation of Teaching Questionnaire

Course Evaluation

1. Effectiveness of course materials used

2. Degree of learning in course

3. Fairness of grading system of course as measure of student performance

4. Appropriateness of difficulty of course for its level

5. Overall evaluation of course

Instructor Evaluation

1. Instructor's ability to communicate with students

2. Instructor's interest in student learning

3. Effectiveness of instructor's teaching methods

4. Instructor's organization of course

5. Overall performance of instructor as an educator

\begin{tabular}{|c|c|c|c|c|}
\hline Very Good & Good & Satisfactory & Poor & $\underline{\text { Very Poor }}$ \\
\hline 5 & 4 & 3 & 2 & 1 \\
\hline 5 & 4 & 3 & 2 & 1 \\
\hline 5 & 4 & 3 & 2 & 1 \\
\hline 5 & 4 & 3 & 2 & 1 \\
\hline 5 & 4 & 3 & 2 & 1 \\
\hline
\end{tabular}

$\begin{array}{lllll}5 & 4 & 3 & 2 & 1 \\ 5 & 4 & 3 & 2 & 1 \\ 5 & 4 & 3 & 2 & 1 \\ 5 & 4 & 3 & 2 & 1 \\ 5 & 4 & 3 & 2 & 1\end{array}$

Appendix 2

Correspondence Between SET Questionnaire and Teaching Dimensions Identified by Marsh

\section{SET Items}

1. Effectiveness of course materials used

2. Degree of learning in course

3. Fairness of grading system of course as measure of student performance

4. Appropriateness of difficulty. of course for its level

5. Overall evaluation of course

6. Instructor's ability to communicate with students

7. Instructor's interest in student learning

8. Effectiveness of instructor's teaching methods

9. Instructor's organization of course

10. Overall performance of instructor as an educator
Teaching Dimensions Identified by Marsh

Assignments (readings/texts valuable)

Learning/Value (learned something valuable)

Examinations/Grading (evaluation methods fair/appropriate)

Workload/Difficulty (course difficulty)

Learning/Value (overall course rating)

Instructor enthusiasm (teaching style held interest)

Individual rapport (interested in individual students) Breadth of coverage (gave background of ideas/concepts) Group interaction (encouraged class discussions) Organization/Clarity (objectives stated and pursued) Instructor enthusiasm (overall instructor rating) 